\title{
Equal-Channel Angular Pressing as a New Processing to Control the Microstructure and Texture of Metallic Sheets
}

\author{
Tong Xiao, Hiroyuki Miyamoto*, Toshiyuki Uenoya
}

Department of Mechanical Engineering, Doshisha University, Kyoto, Japan.

Email: "hmiyamot@mail.doshisha.ac.jp

Received May 26 ${ }^{\text {th }}, 2012$; revised June $28^{\text {th }}, 2012$; accepted July $29^{\text {th }}, 2012$

\begin{abstract}
The extended band structures of as-cold-rolled high $\mathrm{Cr}$ steel sheets are recrystallisation-resistant, and tend to become aggregates of the so-called grain colonies as a partially recovered state after final annealing. Such band structures diminish formability and become origin of the so-called ridging. A novel processing will be shown here, which involves strain-path change by introducing one-pass ECAP prior to cold-rolling, and facilitates recrystallisation. Indeed, the recrystallisation temperature was reduced by $100^{\circ} \mathrm{C}$, compared with cold-rolling alone imposing an equivalent strain. Grainscale microshear bands introduced during one-pass ECAP perturbed the banded structures in post-ECAP cold-rolling and enhanced the recrystallisation at the final annealing.
\end{abstract}

Keywords: Severe Plastic Deformation; Equal-Channel Angular Pressing (ECAP); Recrystallisation; Texture; Ferritic Stainless Steel; Strain Path

\section{Introduction}

Ferritic stainless steel sheets have high corrosion resistance and high formability. Compared with austenitic stainless steel, they are immune to stress corrosion cracking (SCC) in the chemical media, including chloride. Thus, they have been widely used in highly corrosive environments near seawater in place of austenitic stainless steel. However, their formability for deep drawing is generally inferior to that of austenitic stainless steel sheets. Another drawback is the so-called ridging, which appears when sheets are subjected to tensile plastic strain in the rolling direction. Ridging is a kind of rumple, and should be eliminated to give a better good appearance and to further formability. The ridging formation mechanism is not completely clarified yet, but several mechanisms proposed are in agreement that ridging is caused by anisotropic plastic flow of the alternating mixed bands of crystallographic texture [1-4]. These bands with similar crystallographic orientation have been called "colony" and are a unique microscopic feature of ferritic stainless steel sheets. Unlike low carbon steel, ferritic stainless steel with high chromium content $(>11$ mass $\%)$ undergoes no or limited phase transformation $(\alpha \rightarrow \gamma)$ during thermo-mechanical processing, which restricts the opportunities for texture randomisation [5]. Since dynamic recovery occurs quickly in body-centered cubic (bcc) metals during hot-rolling, it

${ }^{*}$ Corresponding author. tends to precede recrystallisation, thereby reducing strain energy as a driving force for recrystallisation. During hot and cold-rolling, the columnar grain structure of the as-cast slab is converted into large and highly elongated bands with a stable $\{100\}<011>$ orientation and homogeneous structures. Since these bands store less energy as dislocations during cold-rolling, they are very difficult to recrystallise, and tend to remain as a colony until the final product. Therefore, facilitating recrystallisation in the final annealing to replace $\{100\}<011>$ with finer grains having random orientation leads to both minimizing the ridging and enhancing formability. Several measures in various steps of processing from casting to cold-rolling have been proposed to control texture and reduce the ridging, and they can all be regarded as essentially enhancing recrystallisation at the final annealing by introducing defects as recrystallisation sites [6-8]. Strain-path changes imposing a disproportional strain have been well-known to affect recrystallisation kinetics $[9,10]$, and their effect on ridging was also investigated by employing cross-rolling [11] and spread-rolling [12].

Equal-channel angular pressing (ECAP) is one of the severe plastic deformations (SPD) that emerged as a new process for fabricating bulk ultrafine grained (UFG) or nanocrystalline materials [13]. The present authors applied ECAP, which has mostly been applied to billets, to ferritic stainless sheets for only one pass prior to coldrolling, and demonstrated that the strain path change, by 
the combination of one-pass ECAP and cold-rolling, has a favourable effect in alleviating ridging and enhancing formability [14].

Following our previous results [14], we further examined recrystallisation behaviour, focusing on the stored energy and role of grain-scale heterogeneous structures, such as deformation bands introduced by ECAP.

\section{Experimental}

Hot-rolled sheets of 16 mass $\%$-Cr steel with extremely low $\mathrm{C}, \mathrm{N}(\mathrm{C}+\mathrm{N}<0.01$ mass $\%)$ with a thickness of 4.0 $\mathrm{mm}$ were annealed at $880^{\circ} \mathrm{C}$ for $10 \mathrm{~min}$ in a laboratory furnace. Then, they were ECA-pressed for one pass followed by cold-rolling to a final thickness of $2.0 \mathrm{~mm}$. The die for ECAP has a channel angle of $120^{\circ}$ as shown in Figure 1. ECAP was carried out using a hydraulic press with a maximum load of $2000 \mathrm{kN}$ (Kawasaki Yuko Co.). Lubricant with a high viscosity of $665 \mathrm{~mm}^{2} / \mathrm{s}$ (Dielub TS 700Z, Daido Chemical Co.) was used in ECAP in order to reduce the otherwise very high frictional force between the billet and the ECAP die. Finally, the specimens were annealed by an infrared furnace (ULVAC MILA3000) at several intermediate temperatures from $600^{\circ} \mathrm{C}$ to $1000^{\circ} \mathrm{C}$ to examine recrystallisation behaviour. We compared this with a conventional process without ECAP in which the sheet was cold-rolled from 5.0 to $1.4 \mathrm{~mm}$. According to Furuno et al. [15], an equivalent strain, $\varepsilon_{\mathrm{eq}}$ given by ECAP with a channel angle of $120^{\circ}$, is about 0.6 , and the sum of $\varepsilon_{\text {eq }}$ by ECAP and cold-rolling is about 1.3. The rolling reduction in the conventional process was adjusted so that an equivalent strain $\varepsilon_{\text {eq }}$ was equal to 1.3. A complete flow diagram of both the conventional and new process involving one-pass ECAP is summarised in Figure 2. Microstructures were observed by an optical micrograph and a scanning electron microscope of field emission type (FE-SEM, JSM 7000F), equipped with electron backscattered diffraction (EBSD, Oxford Instrument Co.). Texture after cold-rolling and final annealing was measured by means of conventional X-ray analysis.

\section{Results}

Orientation color maps before and after ECAP were obtained by EBSD from the TD direction (Figure 3). The microstructure before ECAP appears to be a recrystallised state with some elongation in the rolling direction. However, there are large and highly elongated bands with a similar crystallographic orientation [14], which, during hot-rolling, were converted from the columnar grain structures of the as-cast slab. These bands usually transform into grain colonies with a similar $\{100\} / / N D$ orientation (red color in Figure 3) during recrystallisation in hot strip annealing. After one-pass ECAP, dense deformation bands were observed parallel to the shear plane of ECAP inside a number of grains as shown in Figure 3(b). These deformation bands may be grain-scale shear bands, or so-called microshear bands (MSB). The origin and nature of MSB will be discussed later.

Orientation image maps after cold-rolling and final annealing of both ECAP and the conventional processes are compared in Figure 4. Alternative layers of highly extended $\{111\} / / \mathrm{ND}$ and $\{100\} / / \mathrm{ND}$ grains are observed in
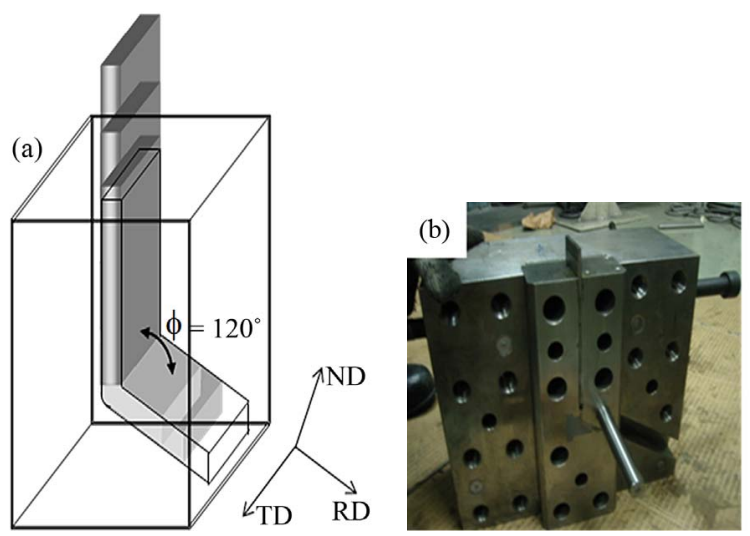

Figure 1. (a) Schematic diagram of ECAP processing. ND, $\mathrm{RD}$ and TD directions are defined with regard to the sheet; (b) Photo of ECAP die.

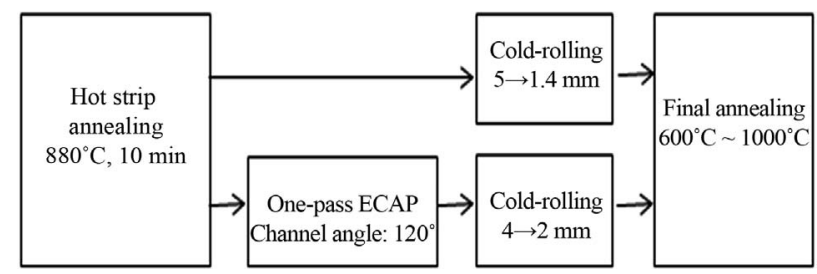

Figure 2. Flow diagram of fabrication process of cold-rolled and annealed sheets by conventional process (upper) and ECAP process (lower).
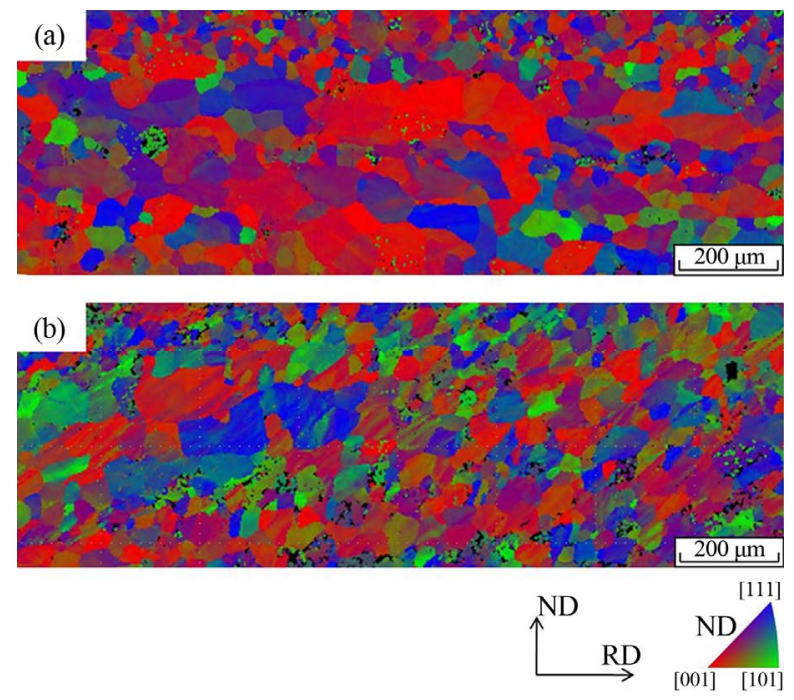

Figure 3. Orientation color maps obtained by EBSD after hot strip annealing and one-pass ECAP. 


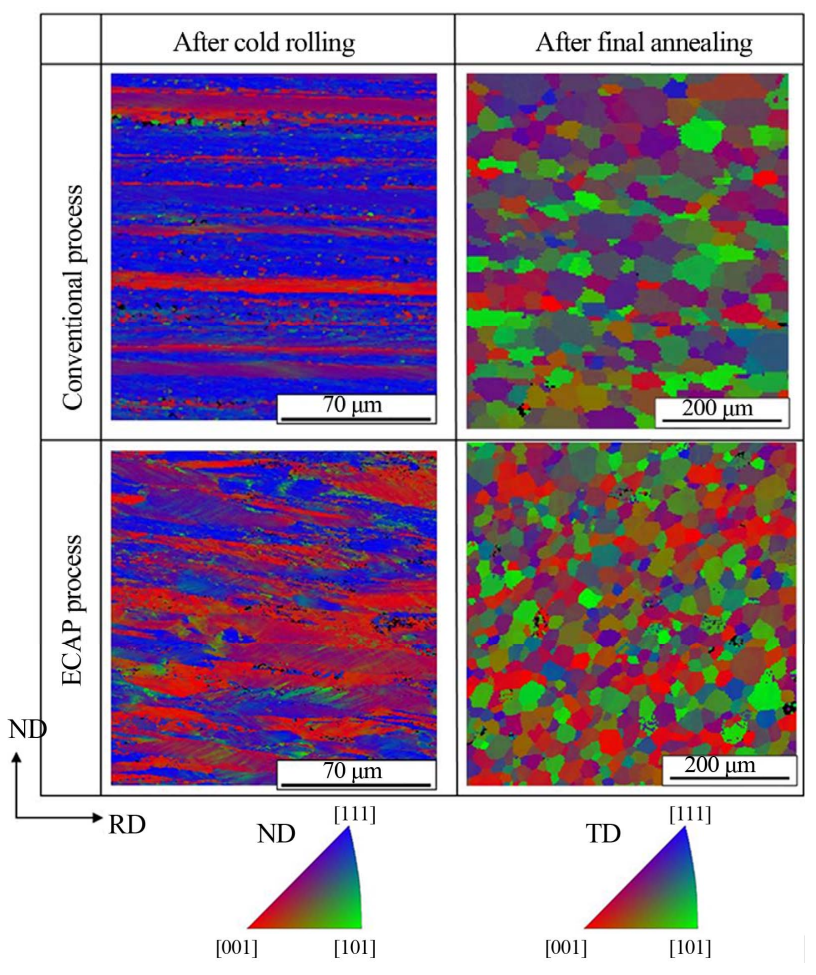

Figure 4. Orientation color maps observed from TD direction after cold-rolling and the final annealing. Orientation is expressed in terms of ND and TD directions, after coldrolling and annealing, respectively.

the conventional process. In the ECAP process, although alternative layers of $\{111\} / / \mathrm{ND}$ and $\{100\} / / \mathrm{ND}$ are similar with the conventional process, very fine band-like structures in a diagonal direction inside the red $\{100\} / / \mathrm{ND}$ grains can be recognized with a slightly different orientation. It is apparent that these band-like structures were the MSB which formed during ECAP, and remained after post-ECAP cold-rolling. Such cold-rolled MSB are not visible inside extended $\{100\} / / \mathrm{ND}$ grains in the conventional process. After the final annealing, somewhat elongated grains with similar crystal orientations were arranged parallel to the rolling direction in the conventional process, whereas grains were smaller and more equiaxed with rather randomly arranged orientations in the ECAP process.

The change of hardness corresponding to an increase of temperature in the final annealing is shown in Figure 5. The cold-rolled sheet in the ECAP process started to soften at a much lower temperature, surprisingly at almost $100^{\circ} \mathrm{C}$ lower than that of the conventional process, although the same equivalent strains were imposed in both processes. This indicates that by the strain path change combining one-pass ECAP prior to cold-rolling, more strain energy can be effectively stored, or more heterogeneous structures can be introduced in the extended bands, than by cold-rolling alone. These heterogeneous structures serve as nucleation sites and facilitate the recrystal- lisation of $\{100\} / \mathrm{ND}$ grain colonies, which are otherwise difficult to recrystallise. The data of pure iron imposed on by the same equivalent strain are also shown for compareson. It is interesting to note that recrystallization temperature is not so much affected by strain path change in pure iron. Microstructures observed by optical microscopy are shown in Figure 6. The cold-rolled band structures are still observed at $800^{\circ} \mathrm{C}$ and $850^{\circ} \mathrm{C}$ in the conventional process, while they were partially recrystallized at $800^{\circ} \mathrm{C}$ and fully recrystallised at $850^{\circ} \mathrm{C}$ in the ECAP process. Therefore, it is evident that the recrystallisation temperature is reduced in the ECAP process.

Texture before and after cold-rolling was shown by $\{100\}$ pole-figures as shown in Figure 7. After cold-rolling, both processes showed typical cold-rolled textures with main $\alpha$-fiber consisting of $<100>/ / R D$ orientations. However, the $\{100\}<011>$ orientation was somewhat higher in the ECAP process than in the conventional process. This result is consistent with the orientation color map after cold-rollings shown in Figure 4, where $\{100\} / / N D$ grains with red color occupy a large fraction of the entire map. Since cold-rolled grains of stable $\{100\}<011>$ orientation are difficult to recrystallise, this result seems to be inconsistent with the enhanced recrystallisation in the ECAP process. After the final annealing, however, the $\gamma$-fiber, i.e., $\{111\} / / \mathrm{ND}$, was somewhat stronger in the ECAP process than in the conventional one. It means that most fractions of $\{100\} / / N D$ grains were replaced by $\{111\} / / \mathrm{ND}$ grains during the recrystallisation process. Therefore, it can be considered that the enhanced recrystallisation in the final annealing in the ECAP process was not attributed to the texture effect, but to the modification of deformation substructures embedding MSB by means of the combination of ECAP and cold-rolling.

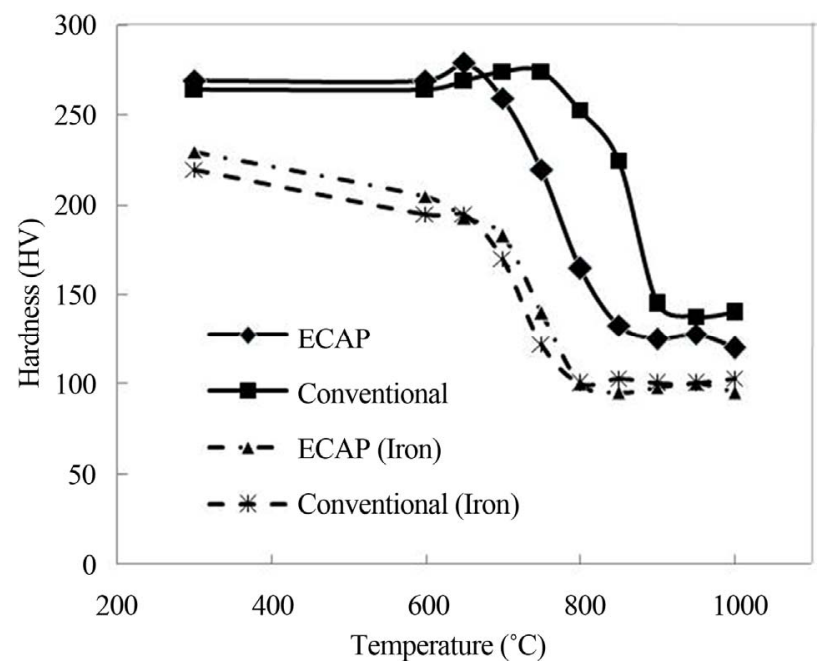

Figure 5. Influence of annealing temperature on hardness of ECAP and the conventional processes. Data of pure iron by same processing are also shown for comparison. 


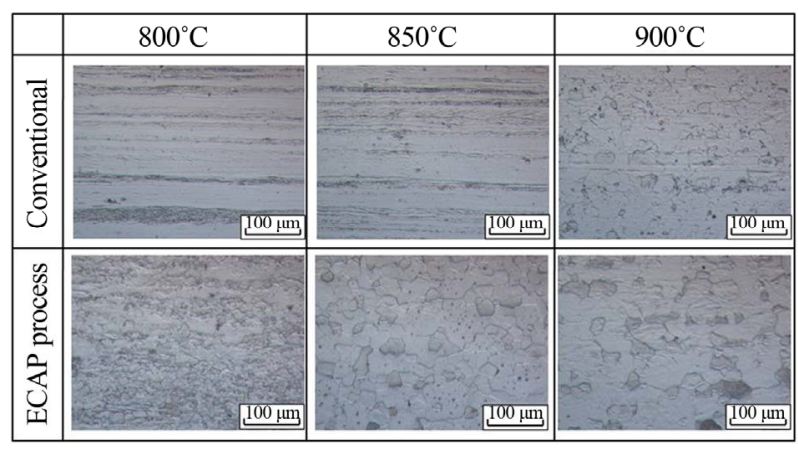

Figure 6. Microstructures by optical microscopy after final annealing showing partially and fully recrystallised states in (a) Conventional and (b) ECAP processes.

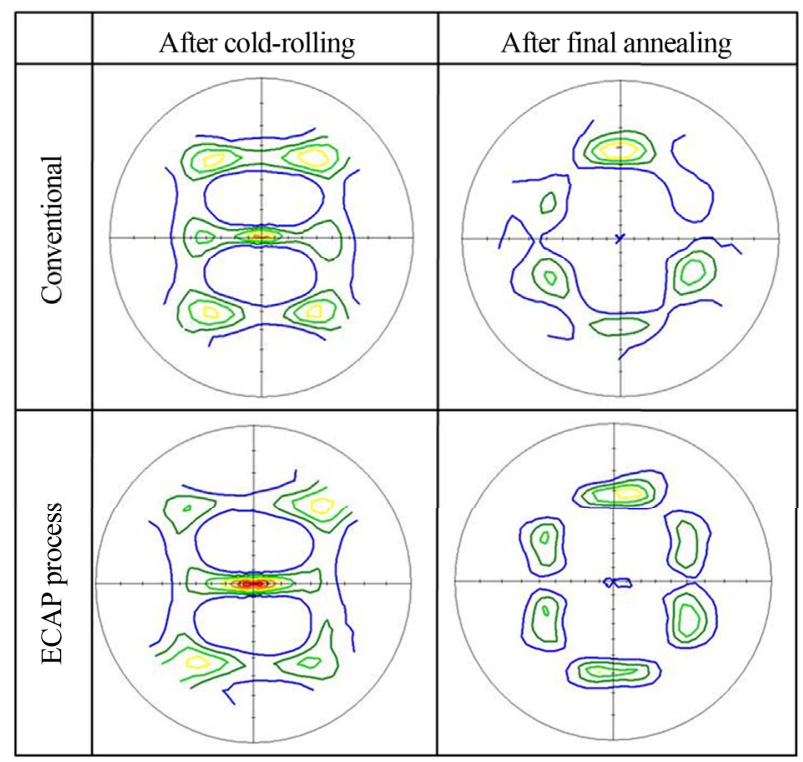

Figure 7. $\{100\}$ pole-figures showing textures after cold-rolling and final annealing in conventional and ECAP process.

\section{Discussion}

It is generally accepted that the strain path change affects the kinetics of static recrystallisation, and as a general trend, the deformation of the forward and reverse directions involving strain reversal causes a retardation of the recrystallisation, as compared to that of a monotonic deformation of the same total strain applied [16-21]. Retarded recrystallisation by strain path change has mostly been discussed in terms of stored energy during the prior deformation. Stored energy can be related to the substructure formed during deformation with dislocation density, sub-boundary misorientation [22]. Redundant or reversed strains retard recrystallisation because they lead to the dissolution of sub-boundaries and dislocation annihilation [23]. For multiaxial deformation and combined modes of deformation, the literature on the effect of strain on recrystallisation has been limited. Embury et al. found that a copper specimen deformed by multi-axial compression recrystallised more slowly than the specimens deformed by monotonic compression for the same equivalent strain [10]. Cowan et al. using torsion combined with reverse torsion or axial compression in aluminum confirmed the profound influence of reverse straining on recrystallisation, but observed almost no deviant effect of torsion + compression (orthogonal state) [24]. Thus, these multi-axial or combined modes of deformation can be considered to reduce recrystallisation kinetics more or less.

Embury et al. [10] described that strain-path change influences recrystallisation in three ways, i.e., 1) The pattern of flow during deformation and resulting spatial distribution of recrystallisation; 2) The work hardened state, namely dislocation density and structures; and 3) the introduction of localised shear bands, which perturb the existing deformed structures. The first effect can be ruled out since the change of flow pattern should lead to a drastic change in the cold-rolled texture. Indeed, $\{100\} / / \mathrm{ND}$ orientation became stronger in the cold-rolled texture in the ECAP process. This orientation, however, is rather recrystallisationresistant. Thus, in this context, texture change is not directly associated with enhanced recrystallisation. The second effect is directly associated with the energy stored by substructure. Since hardness before the final annealing is almost equal in the two processes, as shown in Figure 5 , the difference in the stored energy is not large enough to become a factor enhancing recrystallisation kinetics. Therefore, the third effect by grain-scale MSB may become the most influential one as a result of the strain path change combining one-pass ECAP and cold-rolling. It is well estabmlished that the localized shear band serves as a preferential nucleation site $[9,25]$.

The origin of grain-scale MSB has two possibilities [14]. One is the deformation band as referred to in the usual sense. Deformation bands develop when neighboring volumes of a grain deform on different slip systems and rotate to a different end rotation [26]. The regions between deformation bands are called transition bands having a large orientation gradient that is an ideal site for recrystallisation [26]. However, misorientation across a transition band is generally a few degrees [26], and is much smaller than the one between MSB and the matrix in our experiment [14]. The second possibility is that MSB appears as a manifestation of plastic instability inside a grain (Figure 8(a)). Hurley and Humphreys [27] reported that misorientation across the boundaries between MSB and the matrix was higher than that of cell boundaries, and that it increases with a growing plastic strain forming high-angle grain boundaries (HAGB) as shown in Figure 8(b). It should be pointed out that dislocation boundaries composing MSB consist of geometrically necessary dislocations (GND), which accumulate with increasing misorientation across the dislocation boundary [28]. In ECAP, where simple shear deformation occurs in a very narrow 
region, limited slip systems tend to be activated parallel to the macroscopic shear plane and the shear direction of ECAP [29]. With a limited slip system, material deforms with little strain hardening, accompanying plastic instability with strain localization. Thus, MSB tends to occur in ECAP as a manifestation of plastic instability [29]. The schematic diagram in Figure 9 summarizes the formation mechanism of banded structures with embedded MSB inside stable $\{100\}<011>$ grains. Finally, it is important to note that MSB did not recombine with the matrix during the post-ECAP cold-rolling.

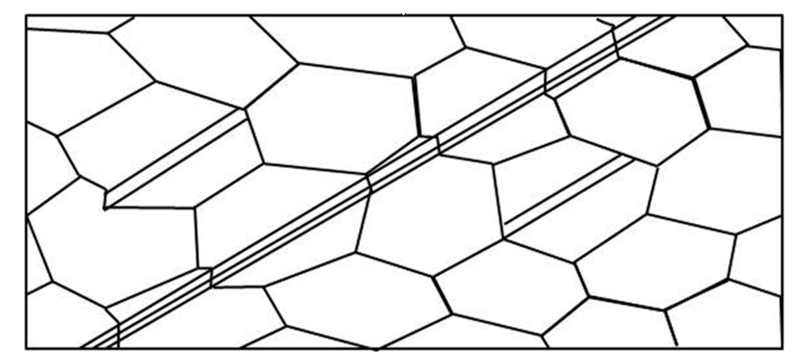

(a)

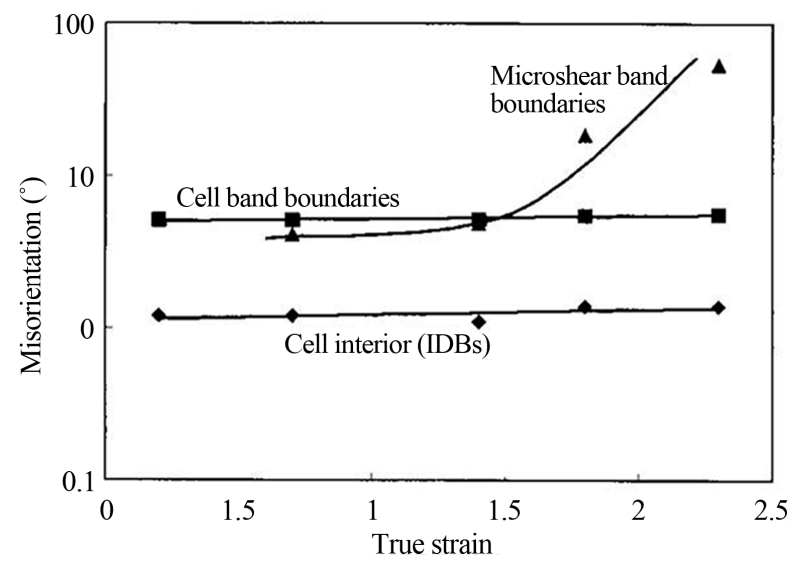

(b)

Figure 8. (a) Schematic diagrams of shear band and grainscale microshear bands; (b) Effect of strain on the mean misorientations of cell, microshear bands in $\mathrm{Al}-0.1 \% \mathrm{Mg}$ [27].

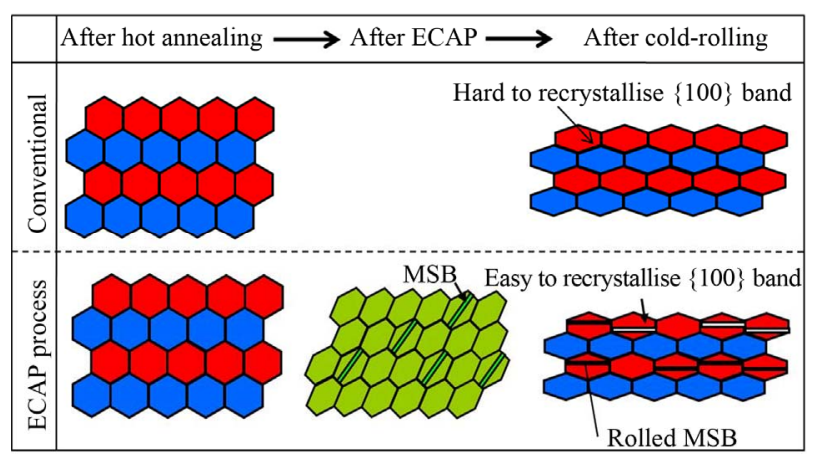

Figure 9. Schematic diagram showing fragmenting process by embedding grain-scale microshear bands in extended $\{100\} / / N D$ grains. Fragmented $\{100\} / / N D$ grains become readily recrystallised on subsequent annealing.

\section{Conclusion}

Recrystallisation has been enhanced in the final annealing by introducing one-pass ECAP prior to cold-rolling in the 16 mass $\% \mathrm{Cr}$ steel sheet. It was found that recrystallisation temperature was reduced almost $100^{\circ} \mathrm{C}$ as compared with the conventional processing without ECAP. Grain-scale microshear bands that developed during ECAP remained after post-ECAP cold-rolling inside the hard-torecrystallise $\{100\}$ grains. These bands are considered to become the nucleation site of recrystallisation and facilitate fragmentation of the colony.

\section{REFERENCES}

[1] T. Ohashi, "The Origin of Ridging in 17\% Cr Stainless Steel Hot-Strips," Journal of Japan Institute of Metal, Vol. 31, No. 4, 1967, pp. 519-525.

[2] H. Takechi, H. Kato, T. Kakunami and T. Nakayama, "On the Mechanism of Ridging Phenomenon in 17\% Chromium Stainless Steel Sheets," Journal of Japan Institute Metal, Vol. 31, No. 6, 1967, pp. 717-723.

[3] R. N. Wright, "Anisotropic Plastic Flow in Ferritic Stainless Steels and the 'Roping' Phenomena," Metallurgical Transactions, Vol. 3, No. 1, 1972, pp. 83-91. doi:10.1007/BF02680588

[4] H. C. Chao, "Recent Studies into the Mechanism of Ridging in Ferritic Stainless Steels," Metallurgical Transactions, Vol. 4, No. 4, 1973, pp. 1183-1186. doi:10.1007/BF02645630

[5] O. M. Engler, Y. Huh and C. N. Tome, "Crystal-Plasticity Analysis of Ridging in Ferritic Stainless Steel Sheets," Metallurgical Materials Transactions, Vol. 36A, No. 11, 2005, pp. 3127-3139. doi:10.1007/s11661-005-0084-5

[6] T. Tsuchiyama, R. Hirota, K. Fukunaga and S. Takaki, "Ridging-Free Ferritic Stainless Steel Produced through Recrystallization of Lath Martensite," ISIJ International, Vol. 45, No. 6, 2005, pp. 923-929. doi:10.2355/isijinternational.45.923

[7] N. Tsuji, K. Tsuzaki and T. Maki, "Effect of Initial Orientation on the Recrystallization Behavior of Solidified Columnar Crystals in 19\% Cr Ferritic Stainless Steel," ISIJ International, Vol. 33, No. 7, 1993, pp. 783-792. doi:10.2355/isijinternational.33.783

[8] M. Y. Huh and O. Engler, "Effect of Intermediate Annealing on Texture, Formability and Ridging of $17 \% \mathrm{Cr}$ Ferritic Stainless Steel Sheet," Materials Science and Engineering A, Vol. 308, No. 1-2, 2001, pp. 74-87. doi:10.1016/S0921-5093(00)01995-X

[9] M. K. Haouaoui, T. Hartwig and A. E. Payzant, "Effect of Strain Path on Texture and Annealing Microstructure Development in Bulk Pure Copper Processed by Simple Shear," Acta Materialia, Vol. 53, No. 3, 2005, pp. 801810. doi:10.1016/j.actamat.2004.10.032

[10] J. D. Embury, W. J. Poole and E. Koken, "Some Views on the Influence of Strain Path on Recrystallization," Scripta Materialia, Vol. 27, No. 11, 1992, pp. 1465-1470. doi:10.1016/0956-716X(92)90129-3 
[11] J. H. Lee, S. H. Park and M. Y. Huh, "Modification of the Recrystallization Texture by Means of Cross Rolling in Ferritic Stainless Steel Sheets," Materials Science Forum, Vol. 449-452, 2004, pp. 1-6. doi:10.4028/www.scientific.net/MSF.449-452.1

[12] T. Kaneko, H. Utsunomiya, Y. Saito, T. Sakai and N. Furushiro, "Improvement of Ridging Behavior of Ferritic Stainless Steel by Spread Rolling Method," Tetsu-toHagane, Vol. 89, No. 6, 2003, pp. 653-658.

[13] R. Z. Valiev and T. G. Langdon, "Principles of EqualChannel Angular Pressing as a Processing Tool for Grain Refinement," Progress in Materials Science, Vol. 51, No. 7, 2006, pp. 881-981. doi:10.1016/j.pmatsci.2006.02.003

[14] H. Miyamoto, T. Xiao, T. Uenoya and M. Hatano, "Effect of Simple Shear Deformation Prior to Cold-Rolling on Texture and Ridging of $16 \%$ Cr Ferritic Stainless Steel Sheets," ISIJ International, Vol. 50, No. 11, 2010, pp. 1653-1659. doi:10.2355/isijinternational.50.1653

[15] K. Furuno, K. Akamatsu, K. Oh-Ishi, M. Furukawa, Z. Horita and T. G. Langdon, "Microstructural Development in Equal-Channel Angular Pressing Using 60 Die," Acta Materialia, Vol. 52, No. 9, 2004, pp. 2497-2507. doi:10.1016/j.actamat.2004.01.040

[16] Q. Zhu and C. M. Sellars, "Effect of Deformation Paths on Static Recrystallization Behavior of an Al-2Mg Alloy," Proceedings of the 3rd International Conference on Recrystallisation and Related Phenomena, Monterey, 21-24 October 1996, pp. 195-202.

[17] R. L. Higginson and C. M. Sellars, "The Effect of Strain Path Reversal during Hot Rolling on Austenitic Stainless Steel," Materials Science and Engineering A, Vol. 338, No. 1-3, 2002, pp. 323-330. doi:10.1016/S0921-5093(02)00088-6

[18] R. Lindh, B. Hutchinson and S. Ueyama, "Effect of Redundant Deformation on Recrystallization Behavior of Copper," Scripta Metallurgica et Materialia, Vol. 29, No. 3, 1993, pp. 347-352. doi:10.1016/0956-716X(93)90511-P

[19] M. P. Black, R. L. Higginson and C. M. Sellars, "Effect of Strain Path on Recrystallization Kinetics during Hot Rolling of Al-Mn," Materials Science and Technology, Vol. 17, No. 9, 2001, pp. 1055-1060.

[20] D. T. McDonald, P. S. Bate and W. B. Hutchinson, "Effect of Strain Path Change on Recrystallization in
Copper," Materials Science and Technology, Vol. 21, No. 6, 2005, pp. 693-700. doi:10.1179/174328405X43171

[21] Z. Lu, "The Effect of Strain Path Change on Recrystallization Temperature," Proceedings of the International Symposium of Young Scholars on Mechanics and Material Engineering for Science and Experiments, Changsha, 1116 August 2001, pp. 561-564.

[22] C. M. Sellars and Q. Zhu, "The Effect of Strain Path on Mechanical Behavior and Microstructure," Proceedings of 20th Riso International Symposium on Materials Science, Deformation-Induced Microstructures, Analysis and Relation to Properties, Roskilde, 6-10 September 1999, pp. 167-182.

[23] T. Hasegawa and T. Yakou, "Forward and Reverse Rearrangements of Dislocations in Tangled Walls," Materials Science and Engineering, Vol. 81, No. 1-2, 1986, pp. 189-199. doi:10.1016/0025-5416(86)90262-4

[24] J. R. Cowan, R. L. Higginson, W. B. Hutchinson and P. S. Bate, "Recrystallisation Following Non-Proportional Straining in Aluminum," Materials Science and Technology, Vol. 11, No. 11, 1995, pp. 1104-1109. doi: $10.1179 / 026708395790164517$

[25] J. Hjelen, R. Orsund and E. Nes, "On the Origin of Recrystallization Textures in Aluminium," Acta Metallurgica et Materia, Vol. 39, No. 7, 1991, pp. 1377-1404. doi:10.1016/0956-7151(91)90225-P

[26] F. J. Humphreys and M. Hatherly, "Recrystallisation and Related Annealing Phenomena," 2nd Edition, Elsevier, Oxford, 2004, pp. 41,259.

[27] P. J. Hurley and F. J. Humphreys, "The Application of EBSD to the Study of Substructural Development in a Cold-Rolled Single-Phase Aluminum Alloy," Acta Materialia, Vol. 51, No. 4, 2003, pp. 1087-1102. doi:10.1016/S1359-6454(02)00513-X

[28] D. A. Hughes and N. Hansen, "Microstructure and Strength of Nickel at Large Strains," Acta Materialia, Vol. 48, No. 11, 2000, pp. 2985-3004. doi:10.1016/S1359-6454(00)00082-3

[29] H. Miyamoto, A. Vinogradov, S. Hashimoto and R. Yoda, "Formation of Deformation Twins and Related Shear Bands in Copper Single Crystal Deformed by EqualChannel Angular Pressing for One Pass at Room Temperature," Materials Transactions, Vol. 50, No. 8, 2009, pp. 1924-1929. doi:10.2320/matertrans.M2009054 